\title{
Synthesis and Optimisation of A Sustainable Wastewater Treatment Plant via Material Flow Cost Account (MFCA)-based Approach
}

\author{
Run Ting Siew ${ }^{1}$, Yoke Kin Wan ${ }^{1, *}$, and Viknesh Andiappan ${ }^{2}$ \\ ${ }^{1}$ School of Engineering, Taylor's University, Subang Jaya, Selangor, Malaysia. \\ ${ }^{2}$ School of Engineering and Physical Sciences, Heriot-Watt University Malaysia, 62200, Putrajaya, \\ Wilayah Persekutuan Putrajaya, Malaysia
}

\begin{abstract}
In this work, MFCA-based approach has been developed to synthesise an optimum wastewater treatment plant (WWTP). To develop the approach, a series of mathematical equations have been generated based on a generic superstructure that presented all possible pathways of WWTP. In this work, four continuous treatment stages (pre-treatment, chemical treatment, biological treatment and tertiary treatment) with various treatment technologies have been considered. In addition, raw material cost, energy cost, labour cost, and waste management cost as well as the hidden cost and carry-forward cost have also been considered in this approach. In this work, hidden cost is referred to the cost that associated with the process stream, while the carry-forward cost is referred to the cost that is carried forward from one process to another process. Furthermore, pollutants (e.g., TSS, COD, BOD and O\&G) have also been considered to ensure the discharged water is complied with discharged regulations. To illustrate the developed approach, an industrial case study, has been solved. As results, an optimum sago wastewater treatment process with minimum waste generation cost is synthesised via a commercial optimisation software, LINGO.
\end{abstract}

\section{Introduction}

Due to the dramatic rise of human population and the rapid growth of industries, waste production rate is getting higher. Generally, wastes can be divided into organic waste (e.g., municipal solid waste (MSW), sewage wastewater, food wastes, etc.) and inorganic waste (e.g., electronic waste, plastics, pesticide, cans, metals, chemical wastes, etc.). Organic waste refers to the waste that consist of biodegradable materials meanwhile inorganic wastewater refers to the waste that consist of relative stable substances which cannot easily degradable by organisms [1]. According to Hoornweg et al. [2], three million tonnes of wastes was produced per day in year 2000, and this amount is expected to hit 6 million tonnes by year 2025 . Thus, waste management is a crucial step to reduce environmental issues and to increase economic performance of an industry. Waste management involves

* Corresponding author: YokeKin.Wan@taylors.edu.my 
various types of treatment processes to ensure the treated wastes complied with discharged regulations before being discharged to the environment.

Among the wastes above-mentioned, organic wastewater is the most common waste generated from industries and households daily. This is because huge amount of water is being used daily for cleaning purpose in industrial processes and household's activity. Numerous research works have been conducted for wastewater treatment technologies. Gobel et al. [3] evaluated elimination of pollutants in secondary (e.g., activated sludge, fludized bed reactor (FBR) and membrane bioreactor (MBR)) and tertiary treatment (e.g., sand filter). Performance of upflow anaerobic sludge blanket (UASB) also being evaluated by Manjunath et al. [4]. Besides that, Mamais et al. [5] and Ekama et al. [6] had researched removal of colloidal matter by using flocculation-precipitation method. Chen et al. [7] and Edzwald et al. [8] had reviewed electrochemical technologies and DAF treatment in WWTP respectively. Other than that, Lefebure et al. [9] also had reviewed physicochemical treatments. Sustainability of treatment technologies such as mechanical, lagoon and land treatment system in WWTP also being evaluated by Muga et al. [10]. Microbial fuel sells (MFC) hybrid process being proposed by Li et al. [11] for sustainability of wastewater treatment process. In optimisation of WWTP technology, Finger et al. [12] had evaluated grit removal performance by varying operating conditions, whereas Al-Mutairi et al. [13] conducted research on coagulant selection and sludge conditioning on slaughterhouse WWTP. These showed that there are various different treatment technologies can be used to treat organic wastewater.

Apart from the conventional technologies, some research works have been done on new technologies. Gogate et al. [14] highlighted on newer technologies of biological oxidation processes (cavitation, photocatalytic oxidation, Fenton's chemistry, ozonation and hydrogen peroxide) and the comparison among different WWTP using Life Cycle Approach (LCA) had been done by Kalbar et al. [15]. Furthermore, different modelling on WWTP also had been done. Wilas et al. [16] based on plant capacities calculation and effluents standards for selection of treatment technology, Woods et al. [17] evaluated economic viable of phosphorus recovery processes, Gernaey et al. [18] focused on modelling of WWTP using white-box model, black-box, stochastic grey-box, and hybrid modelling. Apart from that, Albino et al. [19] used enterprise input-output model. Modelling on UASB performance being conducted by Singh et al. [20]. This showed that modelling is one of the vital tool for treatment technologies selection. In economic aspect, cost modelling (operating cost and maintenance cost) for wastewater treatment process had conducted by Hernendez-Sancho et al. [21]. For optimisation of wastewater treatment plant control, Durrenmatt et al. [22] had built software sensors based on SCADA system of plant. In environmental aspect, Corominas et al. [23] had evaluated Greenhouse Gas Emission (GHG) of entire WWTP by comparing different modelling approaches (1. simple comprehensive model from empirical assumptions and 2. sophisticated model consist of Anaerobic Digestion Model 1 and also biological reactor).

As above-mentioned, many researches had been done on wastewater treatment technologies in aspect of removal efficiency, selection based on performance and optimum operating condition. Meanwhile, development and research on new wastewater treatment technologies also getting more interested on research field. All this imply that wastewater treatment are getting more important. Research on selection of wastewater technologies by modelling also had been done by using input-output model which take consideration on material and energy flows of production process. Apart from that, modelling on economic aspect, environmental aspect and optimisation on process control had also been done. Note that although many researches had done on WWTP technologies and modelling of WWTP processes, however selection of optimum wastewater treatment pathway based on MFCA 
concept which considered hidden cost of waste stream and product stream haven't be applied.

MFCA is Environmental Management Accounting (EMA) for material efficiency analysis of the process [24]. It focused on material flow, energy used and cost accounting [25]. Material cost, energy cost, system cost (e.g., labour cost, depreciation cost) and waste management cost being considered in cost accounting [26]. Significant of MFCA is hidden profits from waste generated can be determined so that further improvement can be done [26]. This is due to the fact that material cost is roughly similar around the world whereas labour cost, energy cost vary significantly by different countries [25]. Thus, MFCA can be the useful tool for cost reduction, higher material and energy management [25]. By doing this, value of corporate can be enhanced. Other than that, MFCA can be the management tool for green productivity since higher energy efficiency also imply that lesser $\mathrm{CO}_{2}$ or waste will be generated from process so environmental performance can be maximised [26]. By concluding benefits above, MFCA account for both economic and environment aspects which lead to sustainability performance [26]. In September 2011, MFCA had become international standard (ISO 14051) and its application is expected to be increased in future [25].

MFCA had been successfully applied on different fields. These fields included lens manufacturing process, printing process, ceramics tiles manufacturing, Canon firm manufacturer and many more. In most recently, Wan et al. [27] developed MFCA-based approach for prioritisation of waste recovery. Two new costs terms were introduced by Wan et al. [27], which is hidden cost and carry-forward cost using the concept of MFCA. MFCA is a concept that focuses on distribution of imputing cost to waste streams. The main purpose of MFCA is to minimise environmental impact concurrently improve economic performance with the selection of minimum total hidden cost of waste stream [27]. Since MFCA concept focused on tracking in amount, quality and cost aspects of input and output material flow in processes, there are 4 types of cost considered in MFCA which are material, system, energy and waste management costs. Waste management is also taken into consideration since waste is considered as one of the by-product in MFCA concept. Attribution of energy, material and system cost are based on the distribution percentage of material toward product and waste stream. These costs were used to determine the hidden cost and carry-forward cost. Hidden cost is the summation cost of processing cost and carry-forward cost. Material, energy and system cost attributed to processing cost. Cost associated to recycle stream or intermediate stream was identified as carry-forward cost. In conventional cost accounting concept, hidden cost that allocated to waste which consists significant cost is overlooked which might affect the final analysed result. Thus, in MFCA, each waste stream has its associated hidden cost which represents its cumulative cost invested to generate these waste. Consideration of hidden cost make MFCA concept more suitable for waste stream prioritisation selection than other accounting prioritisation approaches.

Hence, this research aimed to develop a MFCA-based approach to synthesise an optimum wastewater treatment process with minimum waste generation cost using the concept of MFCA. The significant of this study is the developed model can be used as decision making tool for technology selection to synthesize an optimum wastewater treatment plant. Meanwhile, it is to ensure the treated water is comply with the discharged regulations. In addition, the MFCA-based approach can be used for any type of wastewater by modifying the parameters. To illustrate the developed approach, an industrial case study is solve. In this work, organic sago wastewater treatment is selected as case study. The rest of this paper is organised as follows: research methodology is first presented which is followed by mass balance equations, contaminant balance equations, and cost computation 
equations of the MFCA-based approach. Then, case study on sago wastewater treatment is solved to illustrate the proposed approach. Finally, conclusion and future work are given at the end of paper.

\section{Methodology}

A generic wastewater treatment superstructure is first developed to show all possible pathway to treat wastewater as shown in Figure 1. Based on this generic superstructure, MFCA-based approach has been developed by formulating mathematical equations for each treatment in WWTP as shown in following sections. These equations included mass balance equation, contaminant equation, and cost computation equations. To demonstrate the developed approach, an industry case study, organic wastewater treatment plant is solved.

\subsection{Generic superstructure of wastewater treatment}

A generic superstructure of wastewater treatment plant is shown in Figure 1 below. As shown, Feedstock $W W$ represents wastewater supply with volumetric flow rate $F^{\text {in }}{ }_{W W}$ is treated through different treatment included pre-treatment $p \in P$, chemical treatment $c \in C$, biological treatment $b \in B$ and tertiary treatment $t \in T$ before convert into product $T W$ which is treated water. With the aid of generic superstructure, a series of equations are formulated in the following sections.

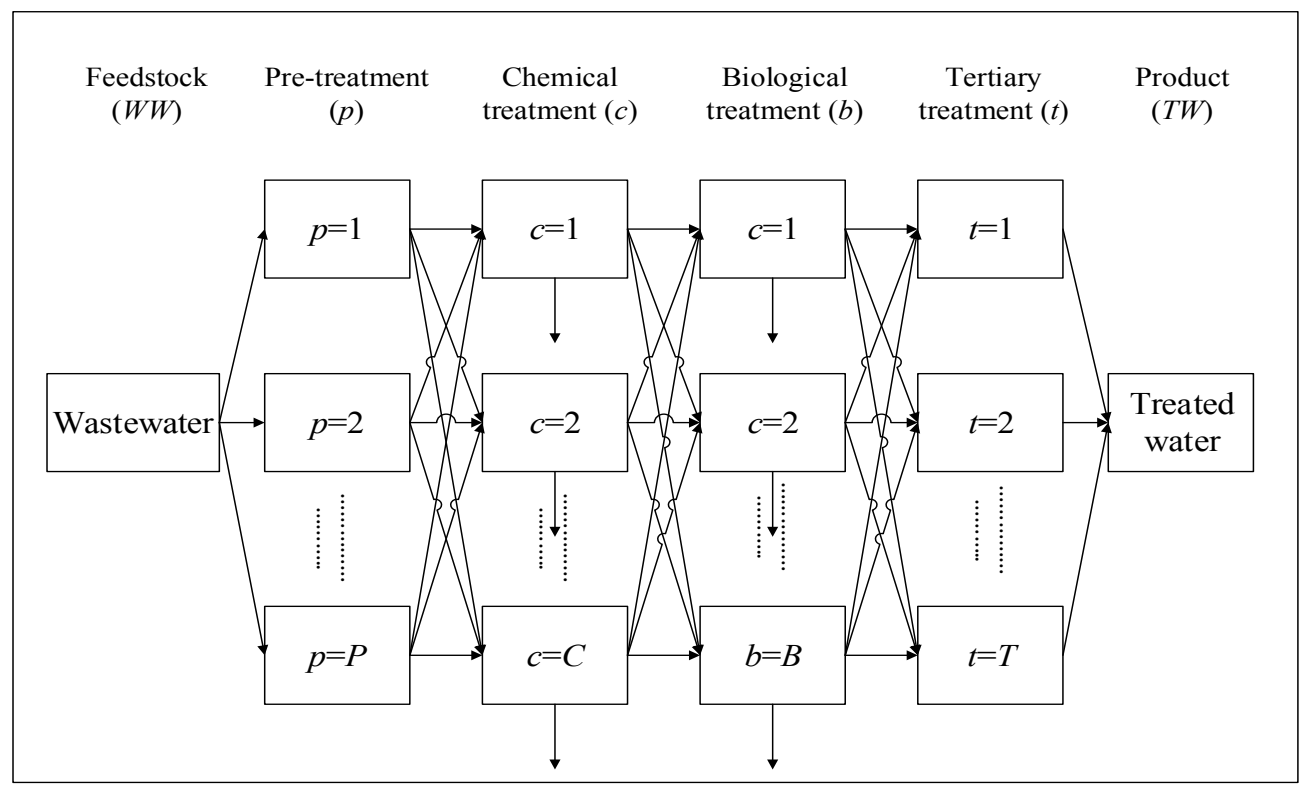

Fig. 1. General superstructure for wastewater treatment. 


\subsection{Mathematical equations}

\subsubsection{Mass balance equations}

As shown in generic superstructure (Figure 1), the total flow rate of feedstock, $f F^{\text {in }}{ }_{W W}$ will be distributed to pre-treatment, $p$ with flowrate of $F^{o u t}{ }_{W W, p}$ as shown in Eq. (1).

$F_{W W}^{i n}=\sum_{p=1}^{n} F_{W W, p}^{o u t}$

$\forall W W$

In other words, the total flowrate that are received by pre-treatment, $p F_{p}^{\text {in }}$ is shown as Eq. (2),

$F_{p}^{i n}=\sum_{W W=1}^{n} F_{W W, p}^{o u t}$

$\forall p$

where $F^{\text {out }}{ }_{W W, p}$ is the feedstock flowrate distributed to pre-treatment, $p$. As a generic rule of mass balance, the inlet flowrate, $F_{p}{ }^{\text {in }}$ must be equal to outlet flowrate $F_{p}{ }^{\text {out }}$ as shown in Eq. (3).

$F_{p}^{i n}=F_{p}^{o u t}$

$\forall p$

In pre-treatment $p$, since it do not produce sludge. Thus, total inlet flow rate of pretreatment, $p$ will be distributed to chemical treatment, $c$ with flowrate of $F_{p, c}$ out as shown in Eq. (4) below. So, total flowrate that received by chemical treatment $c, F_{c}^{i n}$ is shown on Eq. (5). Eq. (6) shown a constraint equation, inlet flowrate, $F_{c}$ in must be equalled to outlet flowrate, $F_{c}^{\text {out }}$.

$$
F_{p}^{i n}=\sum_{c=1}^{n} F_{p, c}^{o u t}
$$

$F_{c}^{i n}=\sum_{p=1}^{n} F_{p, c}^{o u t}$

$\forall c$

$F_{c}^{\text {in }}=F_{c}^{\text {out }}$

$\forall c$

For chemical treatment $c$, since there was additional sludge produced. So other than distribution to biological treatment, $b$ with flowrate of $F_{c, b}$ out , another sludge produced from chemical treatment, $c$ with flowrate of $F_{c}^{\text {sludge }}$ is considered in Eq. (7). 
$F_{c}^{\text {in }}=\sum_{b=1}^{n} F_{c, b}^{o u t}+F_{c}^{\text {sludge }}$

Since there is only one stream that flow through biological treatment $b$, total flow rate received by biological treatment $b, F_{b}$ in can be defined as Eq. (8). Similarly to chemical treatment $c$, a constraint equation as shown in Eq. (9) is set,

$$
\begin{array}{ll}
F_{b}^{\text {in }}=\sum_{c=1}^{n} F_{c, b}^{\text {out }} & \forall b \\
F_{b}^{\text {in }}=F_{b}^{\text {out }} & \forall b
\end{array}
$$

where $F_{b}{ }^{i n}$ is inlet flowrate of biological treatment $b$ and $F_{b}{ }^{\text {out }}$ is outlet flowrate of biological treatment. Besides, there was sludge produced on biological treatment $b$. Thus, total outlet flowrate of biological, $F_{b}{ }^{\text {out }}$ is given as Eq. (10),

$$
F_{b}^{\text {out }}=\sum_{t=1}^{n} F_{b, t}^{\text {out }}+F_{b}^{\text {sludge }}
$$

where $F_{b, t}{ }^{\text {out }}$ is the flowrate of biological treatment, $b$ that will be distributed to tertiary treatment, $t$ and $F_{b}$ sludge is the sludge flowrate produced in biological treatment. Similar to previous case, total flowrate which received by tertiary treatment $t, F_{t}^{\text {in }}$ is shown in Eq. (11). Eq. (12) shown generic rule of mass balance which inlet flowrate of $F_{t}^{\text {in }}$ must be equaled to outlet flowrate of $F_{t}^{\text {out }}$. In addition, Eq. (13) shown the treated water, $T W$ that discharged from tertiary treatment, $t$ with flowrate of $F_{T W}$.

$$
F_{t}^{i n}=\sum_{b=1}^{n} F_{b, t}^{o u t}
$$

$F_{t}^{\text {in }}=F_{t}^{o u t}$

$F_{T W}=\sum_{t=1}^{n} F_{t}^{o u t}$

\subsubsection{Contaminant balance equations on COD}

First, COD concentration at feed inlet is represented in $C^{C O D, i n}{ }_{W W}$ in ppm unit. COD removal efficiency for pre-treatment $p$, chemical treatment $c$, biological treatment $b$ and tertiary treatment $t$ are given as $x_{p}^{C O D}, x_{c}^{C O D}, x_{b}^{C O D}, x_{t}^{C O D}$ respectively. For sludge yield in chemical $c$ and biological treatment $b$ are represented as $Y^{C O D \text {,sludge }}{ }_{c}$ and $Y^{C O D \text {,sludge }}{ }_{b}$, both with unit of $\mathrm{kg}$ sludge/kg COD removed. Sludge density for chemical and biological treatment are represented by $\rho_{c}^{\text {sludge }}$ and $\rho_{b}^{\text {sludge }}$. 
In order to determine the mass of COD, $m_{p}{ }^{C O D, i n}$ at inlet of pre-treatment, $p$ total flow rate received by pre-treatment that determined Eq. (2) is multiplied with COD concentration at feed inlet as shown in Eq. (14).

$$
\boldsymbol{m}_{p}^{C O D, \text { in }}=\boldsymbol{F}_{p}^{i n} \times \mathrm{C}_{W W}^{C O D, \text { in }} \quad \forall p
$$

By using removal efficiency $x_{p}{ }^{C O D}$, outlet COD mass, $m_{p}{ }^{C O D, \text { out }}$ and removal COD mass, $m_{p}{ }^{C O D, R e v}$ from pre-treatment, $p$ can be determined using Eq. (15) and (16).

$$
\begin{array}{ll}
m_{p}^{C O D, \text { out }}=m_{p}^{C O D, \text { in }} \times\left(1-\mathrm{x}_{p}^{C O D}\right) & \forall p \\
m_{p}^{C O D, \mathrm{Rev} v}=m_{p}^{C O D, \text { in }} \times \mathrm{x}_{p}^{C O D} & \forall p
\end{array}
$$

Then, concentration of COD, $C_{p}{ }^{C O D, \text { out }}$ at pre-treatment outlet can be determined via:

$$
C_{p}^{C O D, \text { out }}=\frac{m_{p}^{C O D, \text { out }}}{F_{p}^{\text {out }}}
$$

Next, mass of COD $m_{c}{ }^{C O D, i n}$ at inlet stream to chemical treatment, $c$ can be calculated by using COD concentration obtained above multiplied with distribution of flowrate from pretreatment $p$ to chemical treatment $c, F_{p, c}{ }^{\text {out }}$ which as shown in Eq. (18).

$$
m_{c}^{C O D, \text { in }}=C_{p}^{C O D, \text { out }} \times F_{p, c}^{\text {out }} \quad \forall c
$$

By using removal efficiency $x_{c}{ }^{C O D}$ for chemical treatment $c$, outlet COD mass $m_{c}{ }^{C O D \text {,out }}$ and removal COD mass $m_{c}^{C O D, R e v}$ can be determined as shown on Eq. (19) and (20).

$$
\begin{array}{ll}
m_{c}^{C O D, \text { out }}=m_{c}^{C O D, \text { in }} \times\left(1-\mathbf{X}_{c}^{C O D}\right) & \forall c \\
m_{c}^{C O D, \mathrm{Rev}}=m_{c}^{C O D, \text { in }} \times \mathbf{X}_{c}^{C O D} & \forall c
\end{array}
$$

Based on amount of COD removed in chemical treatment $c$, sludge volumetric flow rate $F_{c}^{\text {sludge }}$ can be determine by using sludge yield $Y_{c}^{\text {COD,sludge }}$ and density $\rho_{c}^{\text {sludge }}$ for chemical treatment $c$ as shown in Eq. (21) below.

$$
F_{c}^{\text {sludge }}=\frac{Y_{c}^{C O D, \text { sludge }}}{\rho_{c}^{\text {sludge }}} \times m_{c}^{C O D, \operatorname{Re} v}
$$


For biological treatment $b$ and tertiary treatment $t$, same procedure can be used to determine COD outlet mass and COD removal from each treatment. Similar to chemical treatment $c$, additional sludge volumetric flow rate need to be account in biological treatment $b$. All equations involved can be represented by Eq. (22) to (30) below.

$$
\begin{aligned}
& C_{c}^{C O D, \text { out }}=\frac{m_{c}^{C O D, \text { out }}}{F_{c}^{\text {out }}} \\
& m_{b}^{C O D, \text { in }}=C_{c}^{C O D, o u t} \times F_{c, b}^{o u t} \\
& m_{b}^{C O D, \text { out }}=m_{b}^{C O D, \text { in }} \times\left(1-x_{b}^{C O D}\right) \\
& \forall c \\
& \forall b \\
& m_{b}^{C O D, \mathrm{Rev}}=m_{b}^{C O D, \text { in }} \times x_{b}^{C O D} \\
& F_{b}^{\text {sludge }}=\frac{Y_{b}^{C O D, \text { sludge }}}{\rho_{b}^{\text {sludge }}} \times m_{b}^{C O D, \operatorname{Re} v} \\
& C_{b}^{C O D, \text { out }}=\frac{m_{b}^{C O D, \text { out }}}{F_{b}^{\text {out }}} \\
& m_{t}^{C O D, \text { in }}=C_{b}^{C O D, o u t} \times F_{b, t}^{o u t} \\
& m_{t}^{C O D, \text { out }}=m_{t}^{C O D, \text { in }} \times\left(1-\mathrm{x}_{t}^{C O D}\right) \\
& \forall b \\
& \forall b \\
& \forall b \\
& \forall b \\
& \forall t \\
& \forall t \\
& \forall t
\end{aligned}
$$

where $C_{c}{ }^{C O D \text {,out }}$ is concentration of COD at chemical treatment outlet, $F_{c}^{\text {out }}$ is outlet flowrate of chemical treatment, $m_{b}{ }^{C O D, \text { in }}$ is mass of COD at inlet stream to biological treatment, $F_{c, b}$ out is distribution of flowrate from chemical treatment to biological treatment, $m_{b}{ }^{C O D \text {, out }}$ is outlet COD mass, $m_{b}{ }^{C O D, R e v}$ is removal COD mass, $x_{b}{ }^{C O D}$ is COD removal efficiency for biological treatment, $F_{b}^{\text {sludge }}$ is sludge flowrate of biological treatment, $C_{b}^{\text {COD, out }}$ is concentration of COD at biological treatment outlet, $F_{b}{ }^{\text {out }}$ is outlet flowrate of biological treatment, $m_{t}^{C O D, i n}$ is COD mass at inlet stream of tertiary treatment, $F_{b, t}$ out is distribution of flowrate from biological to tertiary treatment, $m_{t}^{C O D \text {,out }}$ is outlet COD mass, $m_{t}^{C O D, R e v}$ is removal COD mass and $x_{t}^{C O D}$ is COD removal efficiency at tertiary treatment.

In order to comply with COD discharge standard, outlet COD concentration for tertiary treatment $t, C_{t}^{C O D \text {, out }}$ which is treated water need to be convert from mass that shows on Eq. 
(31). Eq. (32) below shown calculated COD concentration must comply with $C^{S t d, C O D}$ which is standard concentration for COD.

$$
\begin{aligned}
& C_{t}^{C O D, \text { out }}=\frac{m_{t}^{\text {COD,out }}}{F_{t}^{\text {out }}} \\
& C_{t}^{C O D, \text { out }}<C^{S t d, C O D}
\end{aligned}
$$

\subsubsection{Contaminant balance equations on BOD, TSS, O\&G}

Formulation of contaminant balance equation for BOD, TSS and O\&G is same as the formulation of COD balance equation above but just need to replace respective index value into all COD balance equations above.

\subsubsection{Cost computation equations}

Operating cost for technology in each treatment take account of raw material cost, energy cost and labour cost. Thus, operating cost of pre-treatment $p$ Cost $_{p}{ }^{\text {ppt }}$ can be determine as Eq. (33) below.

$$
\operatorname{Cost}_{p}^{\text {mat }}+\operatorname{Cost}_{p}^{\text {enegy }}+\operatorname{Cost}_{p}^{\text {labour }}=\operatorname{Cost}_{p}^{\text {opt }} \quad \forall p
$$

where $\operatorname{Cost}_{p}{ }^{\text {mat }}$ is raw material cost, Cost $_{p}^{\text {energy }}$ is energy cost and Cost $_{p}^{\text {labour }}$ is labour cost. Based on calculated pre-treatment $p$ operating cost, hidden unit cost for pre-treatment UCost $_{p}{ }^{\text {Hidden }}$ can be determined via:

$U \operatorname{Cost}_{p}^{\text {Hidden }}=\frac{\operatorname{Cost}_{p}^{\text {opt }}}{F_{p}^{i n}}$

Carry-forward cost from pre-treatment $p$ to chemical treatment $c, C F C_{p, c}$ can be determined using Eq. (35) below.

$$
C F C_{p, c}=U \operatorname{Cost}_{p}^{\text {Hidden }} \times F_{p, c}^{\text {out }} \quad \forall p \forall c
$$

Similar to operating cost determination of pre-treatment $p$, operating cost of chemical treatment $c, \operatorname{Cost}_{c}{ }^{\text {opt }}$ is determined on Eq. (36) below with an additional carry-forward cost from Eq. (35). By using calculated chemical treatment $c$ operating cost, hidden unit cost of chemical treatment $c$ UCost ${ }_{c}^{\text {Hidden }}$ is calculated using Eq. (37) below.

$$
\operatorname{Cost}_{c}^{\text {mat }}+\operatorname{Cost}_{c}^{\text {enegy }}+\operatorname{Cost}_{c}^{\text {labour }}+\sum_{p=1}^{n} \operatorname{CFC} C_{p, c}=\operatorname{Cost}_{c}^{\text {opt }}
$$


$U \operatorname{Cost}_{c}^{\text {Hidden }}=\frac{\operatorname{Cost}_{c}^{\text {opt }}}{F_{c}^{\text {in }}}$

$\forall c$

where $\operatorname{Cost}_{c}^{\text {mat }}$ is raw material cost, Cost $_{c}^{\text {energy }}$ is energy cost and $\operatorname{Cost}_{c}^{\text {labour }}$ is labour cost for chemical treatment $c$.

In chemical treatment $c$, instead of just carry forward cost from chemical treatment $c$ to biological treatment $b C F C_{c, b}$, there is another hidden cost for sludge generation $H C_{c}^{\text {sludge }}$ as shown in Eq. (38) and (39).

$$
\begin{array}{ll}
C F C_{c, b}=U \operatorname{Cost}_{c}^{\text {Hidden }} \times F_{c, b}^{\text {out }} & \forall c \forall b \\
H C_{c}^{\text {sludge }}=U \operatorname{Cost}_{c}^{\text {Hidden }} \times F_{c}^{\text {sludge }} & \forall c
\end{array}
$$

For biological treatment $b$ and tertiary treatment $t$ same procedure can be used to determine operating cost, hidden unit cost and carry-forward from each treatment. Similar to chemical treatment $c$, additional sludge hidden cost need to be account in biological treatment $b$. All equations involved can be represented by Eq. (40) to (46) below.

$$
\begin{aligned}
& \operatorname{Cost}_{b}^{\text {mat }}+\operatorname{Cost}_{b}^{\text {energy }}+\operatorname{Cost}_{b}^{\text {labour }}+\sum_{c=1}^{n} C F C_{c, b}=\operatorname{Cost}_{b}^{o p t} \quad \forall b \\
& \operatorname{Cos}_{b}^{\text {Hidden }}=\frac{\operatorname{Cost}_{b}^{\text {opt }}}{F_{b}^{\text {in }}} \\
& \forall b \\
& C F C_{b, t}=U \operatorname{Cost}_{b}^{\text {Hidden }} \times F_{b, t}^{\text {out }} \\
& \forall b \forall t \\
& H C_{b}^{\text {sludge }}=U \operatorname{Cost}_{b}^{\text {Hidden }} \times F_{b}^{\text {sludge }}
\end{aligned}
$$

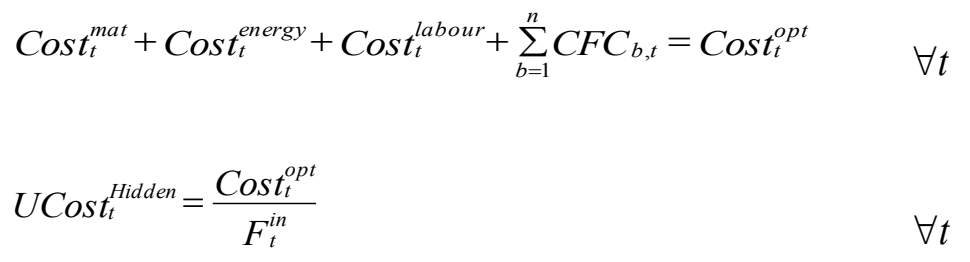

$C F C_{t, T W}=U \operatorname{Cost}_{t}^{\text {Hidden }} \times F_{t}^{\text {out }}$ 
where $\operatorname{Cost}_{b}^{\text {mat }}$, Cost $_{b}^{\text {energy }}$, Cost $_{b}^{\text {labour }}$ and Cost $_{b}{ }^{\text {opt }}$ are raw material cost, energy cost, labour cost and operating cost for biological treatment $b$. UCost ${ }_{b}{ }^{\text {Hidden }}$ is hidden unit cost for biological treatment $b$. Carry-forward cost from biological treatment $b$ to tertiary treatment $t$ and sludge hidden cost for biological treatment $b$ are $C F C_{b, t}$ and $H C_{b}$ sludge respectively. Raw material cost, energy cost, labour cost and operating cost involved in tertiary treatment $t$ are represented by Cost $t_{t}^{\text {mat }}$, Cost $_{t}^{\text {energy }}$, Cost $_{t}^{\text {labour }}$ and $\operatorname{Cost}_{t}^{\text {opt }}$ respectively. UCost ${ }_{t}^{\text {Hidden }}$ is hidden unit cost for tertiary treatment $t, C F C_{t, T W}$ is carry-forward cost from tertiary treatment $t$ to product.

Once cost accounted on all streams around each treatment by using all cost computation equations above, total hidden cost for product and total sludge produced can be determined by Eq. (47) and (48) below.

$$
\begin{aligned}
& H C^{T W}=\sum_{t=1}^{n} C F C_{t, T W} \\
& H C^{\text {Total,sludge }}=\sum_{c=1}^{n} H C_{c}^{\text {sludge }}+\sum_{b=1}^{n} H C_{b}^{\text {sludge }}
\end{aligned}
$$

Hence total hidden cost $H C^{\text {Total }}$ and total operating cost of technology involved in each treatment Cost $^{\text {Total opt }}$ for entire wastewater treatment can be calculated via:

$$
\begin{aligned}
& H C^{\text {Total }}=H C^{T W}+H C^{\text {Total,sludge }} \\
& \operatorname{Cost}^{\text {Total,opt }}=\sum_{p=1}^{n} \operatorname{Cost}_{p}^{\text {opt }}+\sum_{c=1}^{n} \operatorname{Cost}_{c}^{o p t}+\sum_{b=1}^{n} \operatorname{Cost}_{b}^{o p t}+\sum_{t=1}^{n} \operatorname{Cos} t_{t}^{o p t}
\end{aligned}
$$

Finally, optimization objective of this modelling is to minimize $H C^{\text {Total }}$ as shown in Eq. (51) below.

$$
\text { Min }=H C^{\text {Total }}
$$

In order to demonstrate approach that mentioned above, a case study is solved in the following section.

\subsection{Case study}

A sago wastewater treatment is select as case study in this research. Thus, Figure 2 below shows superstructure of organic wastewater treatment with specific technologies listed on different treatment. Based on comprehensive literature review done on organic wastewater treatment technology, typical wastewater treatment technologies used in organic wastewater treatment is adopted as treatment technologies in each treatment stage which presented in Figure 2 below. 


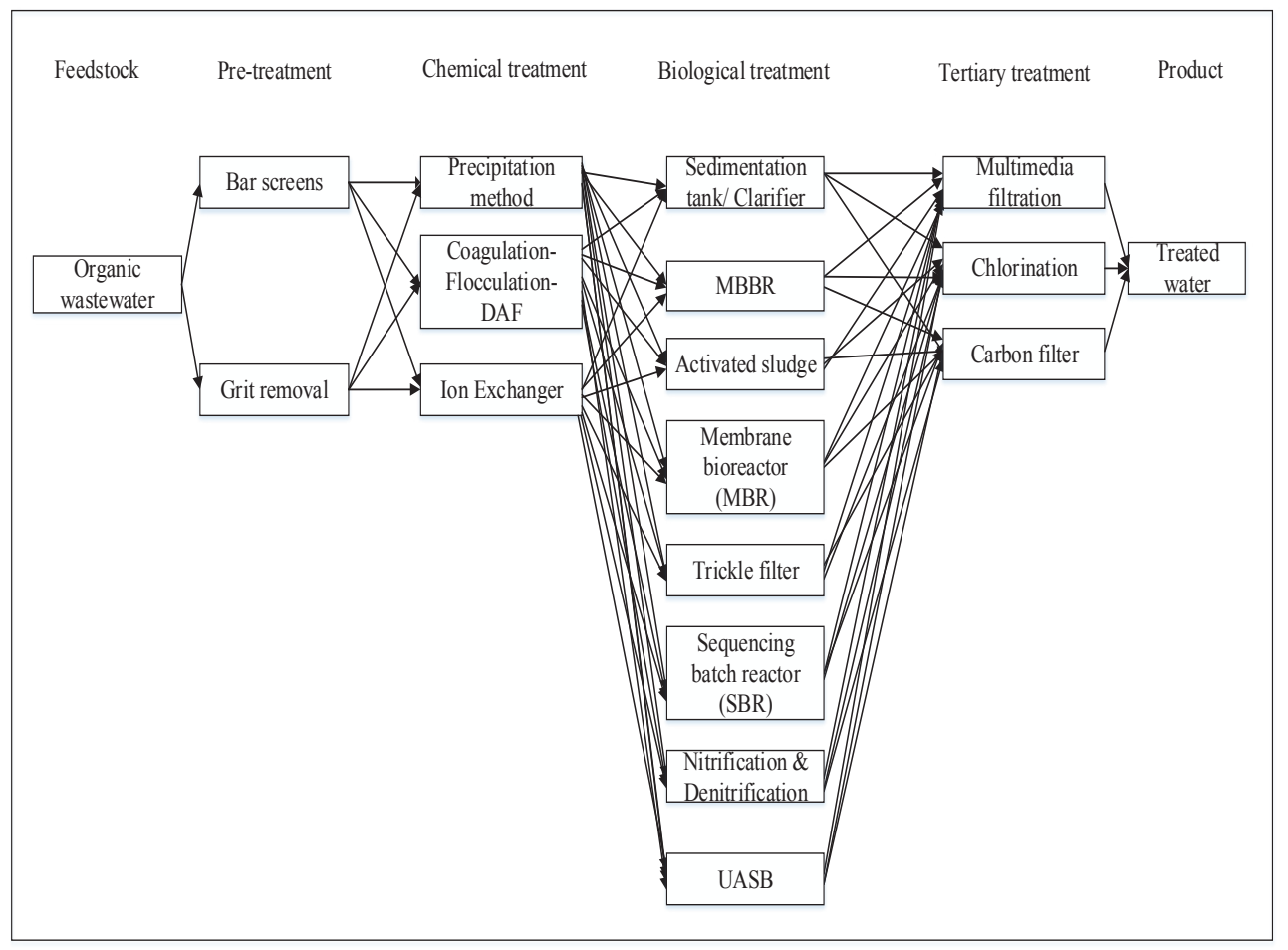

Fig. 2. Superstructure of organic wastewater treatment.

As shown, organic wastewater treatment begins with pre-treatment which consists of bar screen and grit removal. Next is chemical treatment with technologies of precipitation method, coagulation-flocculation-DAF and ion exchanger. Then follow by biological treatment which involved sedimentation tank/clarifier, MBBR, activated sludge and others. Tertiary treatment is the final treatment stage with multimedia filtration, chlorination and carbon filter. Through selection of technology in each treatment stage, treated water that complied with discharged regulation can be generated.

Contaminants characteristic of sago wastewater and discharged regulations are tabulated in Table 1 below. Contaminants characteristics of sago wastewater is based on sago mill industry in Sarawak [28]. Besides that, contaminant removal efficiency of each technology on different treatment stage are summarised in Table 2. Apart from that, in Table 3, operating cost such as raw material cost, energy cost and labour cost in each technology is tabulated.

For energy cost for cost computation listed in each technology on Table 3, it included electricity consumption of pumps, compressors, clarifier and other equipment which involved in that particular treatment. 
Table 1. Sago wastewater contaminants characteristic and discharged regulations [28, 29]

\begin{tabular}{|c|c|c|c|c|}
\hline \multicolumn{5}{|c|}{ Concentration (ppm) } \\
\hline & TSS & COD & BOD & O\&G \\
\hline Sago wastewater & 4800 & 11650 & 5750 & 300 \\
\hline $\begin{array}{c}\text { Discharged } \\
\text { regulations } \\
\text { Standard A) }\end{array}$ & 50 & 50 & 20 & 10 \\
\hline
\end{tabular}

Table 2. Contaminant removal efficiency of technologies.

\begin{tabular}{|c|c|c|c|c|}
\hline \multicolumn{5}{|c|}{ Pre-treatment $[30,31]$} \\
\hline & \multicolumn{4}{|c|}{ Removal efficiency (\%) } \\
\hline & TSS & COD & BOD & $\mathrm{O} \& \mathrm{G}$ \\
\hline Bar screen & 50 & 20 & 35 & 85 \\
\hline Grit removal & 50 & 20 & 30 & 90 \\
\hline \multicolumn{5}{|c|}{ Chemical treatment $[32,33,34,35]$} \\
\hline & \multicolumn{4}{|c|}{ Removal efficiency (\%) } \\
\hline & TSS & COD & BOD & $\mathrm{O} \& \mathrm{G}$ \\
\hline $\begin{array}{l}\text { Precipitation } \\
\text { method }\end{array}$ & 90 & 80 & 80 & 50 \\
\hline $\begin{array}{c}\text { Coagulation- } \\
\text { Flocculation- } \\
\text { DAF }\end{array}$ & 85 & 80 & 70 & 95 \\
\hline Ion exchanger & 0 & 38 & 38 & 20 \\
\hline \multicolumn{5}{|c|}{ Biological treatment $[33,36,37,38,39]$} \\
\hline & \multicolumn{4}{|c|}{ Removal efficiency (\%) } \\
\hline & TSS & COD & BOD & $\mathrm{O} \& \mathrm{G}$ \\
\hline $\begin{array}{c}\text { Sedimentation } \\
\text { tank }\end{array}$ & 70 & 20 & 35 & 20 \\
\hline
\end{tabular}


Table 2. Contaminant removal efficiency of technologies (Cond.).

\begin{tabular}{|c|c|c|c|c|}
\hline \multicolumn{5}{|c|}{ Biological treatment $[33,36,37,38,39]$} \\
\hline & \multicolumn{4}{|c|}{ Removal efficiency (\%) } \\
\hline & TSS & COD & BOD & O\&G \\
\hline MBBR & 0 & 85 & 88 & 0 \\
\hline $\begin{array}{l}\text { Activated } \\
\text { sludge }\end{array}$ & 61 & 72 & 90 & 0 \\
\hline MBR & 99 & 97 & 98 & 0 \\
\hline Trickle filter & 95 & 85 & 90 & 0 \\
\hline SBR & 98 & 85 & 98 & 79 \\
\hline $\begin{array}{l}\text { Nitrification/De } \\
\text { nitrification }\end{array}$ & 0 & 81 & 89 & 0 \\
\hline UASB & 80 & 80 & 85 & 0 \\
\hline \multicolumn{5}{|c|}{ Tertiary treatment $[40,41]$} \\
\hline & \multicolumn{4}{|c|}{ Removal efficiency (\%) } \\
\hline & TSS & COD & BOD & O\&G \\
\hline $\begin{array}{l}\text { Multimedia } \\
\text { filtration }\end{array}$ & 86 & 69 & 67 & 0 \\
\hline Carbon filter & 0 & 30 & 50 & 0 \\
\hline Chlorination & 0 & 10 & 20 & 0 \\
\hline
\end{tabular}


Table 3. Operating cost of technologies.

\begin{tabular}{|c|c|c|c|c|}
\hline \multicolumn{5}{|c|}{ Pre-treatment $[30,31]$} \\
\hline & \multicolumn{4}{|c|}{ Cost (USD/day) } \\
\hline & Raw material & Energy & Labour & Opt. cost \\
\hline Bar screen & 0 & 1668.48 & 174 & 1842.48 \\
\hline Grit removal & 0 & 973.52 & 174 & 1147.52 \\
\hline \multicolumn{5}{|c|}{ Chemical treatment $[33,34,35,38,42]$} \\
\hline & \multicolumn{4}{|c|}{ Cost (USD/day) } \\
\hline & Raw material & Energy & Labour & Opt. cost \\
\hline $\begin{array}{l}\text { Precipitation } \\
\text { method }\end{array}$ & 0.18 & 1264.9 & 632 & 1897.18 \\
\hline $\begin{array}{c}\text { Coagulation- } \\
\text { Flocculation- } \\
\text { DAF }\end{array}$ & 240.87 & 30.6 & 696 & 967.47 \\
\hline Ion exchanger & 472.22 & 97.22 & 175 & 1094.44 \\
\hline \multicolumn{5}{|c|}{ Biological treatment $[33,34,42,43]$} \\
\hline & \multicolumn{4}{|c|}{ Cost (USD/day) } \\
\hline & Raw material & Energy & Labour & Opt. cost \\
\hline $\begin{array}{l}\text { Sedimentation } \\
\operatorname{tank}\end{array}$ & 0 & 184.252 & 175 & 359.252 \\
\hline MBBR & 0 & 695 & 875 & 1570 \\
\hline $\begin{array}{l}\text { Activated } \\
\text { sludge }\end{array}$ & 0 & 9147.3 & 1427 & 10574.3 \\
\hline MBR & 0 & 8295 & 1095 & 9390 \\
\hline Trickle filter & 0 & 5840.565 & 1095 & 6935.57 \\
\hline SBR & 0 & 833.33 & 875 & 1708.33 \\
\hline
\end{tabular}


Table 3. Operating cost of technologies (Cond.)

\begin{tabular}{|c|c|c|c|c|}
\hline \multicolumn{5}{|c|}{ Biological treatment $[33,34,42,43]$} \\
\hline & \multicolumn{4}{|c|}{ Cost (USD/day) } \\
\hline & Raw material & Energy & Labour & Opt. cost \\
\hline $\begin{array}{l}\text { Nitrification/De } \\
\text { nitrification }\end{array}$ & 5039 & 702 & 875 & 6616 \\
\hline UASB & 0 & 4740 & 875 & 5615 \\
\hline \multicolumn{5}{|c|}{ Tertiary treatment $[40,41,43]$} \\
\hline & \multicolumn{4}{|c|}{ Cost (USD/day) } \\
\hline & Raw material & Energy & Labour & Opt. cost \\
\hline $\begin{array}{l}\text { Multimedia } \\
\text { filtration }\end{array}$ & 0 & 1043.5 & 875 & 1918.5 \\
\hline Carbon filter & 67 & 373 & 875 & 1315 \\
\hline Chlorination & 208.33 & 373 & 875 & 1456.33 \\
\hline
\end{tabular}

Based on sago wastewater treatment plant with flowrate of $79,000 \mathrm{~m}^{3} /$ day and the contaminants characteristic as shown in Table 1, mass of TSS, COD, BOD and O\&G are determined as 379,200, 920,350, 454,250 and 23,700 kg/day, respectively. By input respective contaminant removal efficiency and operating cost of each technology into previous mass and cost computation modelling equations, selection among treatment technology has been done by using LINGO software.

As results, technology that gives minimum hidden cost meanwhile comply with discharge regulations is selected in each treatment stage. Table 4 shows concentration of contaminants on selected technology in each treatment stage. Apart from that, in order to ensure the final treated water that discharged from the selected treatment technologies is complied with discharged regulation (standard A), Table 5 is presented to show the comparison between contaminants concentration of treated water with discharged regulation. It can be clear identified that all contaminants concentration of treated water was lower that discharged regulation so it is safe to be discharged to water bodies.

Next, cost computation is being considered using MFCA concept. Results of unit cost, hidden cost and carry-forward cost for each treatment technology selected by solving Eq. (33) - (46) are summarized in Table 6. Since additional sludge being produced in chemical 
and biological treatment, so additional hidden cost being calculated via Eq. (39) and (43). Besides that, total hidden cost of entire WWTP also shown in Table 6.

As shown, minimum total hidden cost (THC) of 12,819.98 USD/day can be achieved by selecting grit removal, coagulation-flocculation-DAF, MBR and carbon filter as treatment technology in entire WWTP. THC is calculated by summation of carry-forward cost from tertiary treatment to treated water, hidden cost for sludge generation of chemical and biological treatment. By referring to cost computation equations in section 2.2.4, calculation of unit cost, carry-forward cost and hidden cost are based on operating cost and volumetric flow rate around each treatment technology. Due to conservation of mass, inlet and outlet volumetric flow around each technology must be equal. Hence, operating cost of technology stands out to be one of the main factor in determine value of hidden cost and carry-forward cost. On other word, higher operating cost will lead to higher hidden cost and carry-forward cost.

Table 4. Contaminants concentration on selected technologies.

\begin{tabular}{|c|c|c|c|c|c|c|}
\hline \multirow[t]{2}{*}{ Treatment } & \multirow[t]{2}{*}{ Technology } & \multirow[t]{2}{*}{ Stream } & \multicolumn{4}{|c|}{ Contaminant concentration (ppm) } \\
\hline & & & TSS & COD & BOD & O\&G \\
\hline \multirow{2}{*}{$\begin{array}{c}\text { Pre- } \\
\text { treatment }\end{array}$} & \multirow{2}{*}{$\begin{array}{c}\text { Grit } \\
\text { removal }\end{array}$} & Inlet & 4800 & 11650 & 5750 & 300 \\
\hline & & Outlet & 2400 & 9320 & 4025 & 30 \\
\hline \multirow{2}{*}{$\begin{array}{l}\text { Chemical } \\
\text { treatment }\end{array}$} & \multirow{2}{*}{$\begin{array}{c}\text { Coagulation } \\
- \\
\text { Flocculation } \\
\text {-DAF }\end{array}$} & Inlet & 2400 & 9320 & 4025 & 30 \\
\hline & & Outlet & 389 & 2014 & 1305 & 1.6 \\
\hline \multirow{2}{*}{$\begin{array}{c}\text { Biological } \\
\text { treatment }\end{array}$} & \multirow{2}{*}{ MBR } & Inlet & 389 & 2014 & 1305 & 1.6 \\
\hline & & Outlet & 4.1 & 64.0 & 27.6 & 1.7 \\
\hline \multirow{2}{*}{$\begin{array}{c}\text { Tertiary } \\
\text { treatment }\end{array}$} & \multirow{2}{*}{$\begin{array}{l}\text { Carbon } \\
\text { filter }\end{array}$} & Inlet & 4.1 & 64.0 & 27.6 & 1.7 \\
\hline & & Outlet & 4.1 & 44.8 & 13.8 & 1.7 \\
\hline
\end{tabular}


Table 5. Comparison between contaminants concentration of treated water with discharged regulations.

\begin{tabular}{|c|c|c|c|c|}
\hline & \multicolumn{4}{|c|}{ Concentration (ppm) } \\
\hline & TSS & COD & BOD & O\&G \\
\hline Treated water & 4.12 & 44.8 & 13.8 & 1.72 \\
\hline $\begin{array}{c}\text { Discharged } \\
\text { regulations }\end{array}$ & 50 & 50 & 20 & 10 \\
\hline
\end{tabular}

Table 6. Results of unit cost, hidden cost and carry-forward cost of each treatment technology.

\begin{tabular}{|c|c|c|c|c|}
\hline \multirow{2}{*}{ Treatment } & \multirow{2}{*}{ Technology } & \multicolumn{3}{|c|}{ Cost (USD/day) } \\
\cline { 3 - 5 } & & Unit cost & $\begin{array}{c}\text { Carry- } \\
\text { forward cost }\end{array}$ & Hidden cost \\
\hline Pre-treatment & Grit removal & 0.0145 & $1,147.52$ & - \\
\hline $\begin{array}{c}\text { Chemical } \\
\text { treatment }\end{array}$ & $\begin{array}{c}\text { Coagulation- } \\
\text { Flocculation- } \\
\text { DAF }\end{array}$ & 0.02677 & $1,957.30$ & 157.69 \\
\hline $\begin{array}{c}\text { Biological } \\
\text { treatment }\end{array}$ & MBR & 0.1552 & $10,709.91$ & 637.38 \\
\hline $\begin{array}{c}\text { Tertiary } \\
\text { treatment }\end{array}$ & Carbon filter & 0.1743 & - & $12,024.91$ \\
\hline \multicolumn{4}{|c|}{ Total hidden cost } & $12,819.98$ \\
\hline
\end{tabular}

In pre-treatment, grit removal is being selected instead of bar screen. This is due to both technologies have comparable contaminants removal efficiency however grit removal provide lower operating cost than bar screen which can be clearly identified on Table 3 .

Among three technologies in chemical treatment, ion exchanger is eliminated due to low contaminants removal efficiency. Although contaminants removal efficiency of precipitation method is similar to coagulation-flocculation-DAF but high operating cost in precipitation method which makes it uneconomical. Thus coagulation-flocculation-DAF is selected as chemical treatment technology.

Even though operating cost for MBR ranked as second highest among technologies in biological treatment, it still selected as technology for biological treatment. The main reason is MBR provide high contaminants removal efficiency especially in COD. Although highest COD removal technology being selected in pre-treatment, chemical treatment and tertiary treatment, up to $87 \%$ of COD removal efficiency technology must be selected for biological treatment in order to meet discharged regulations This imply that technologies in biological treatment having COD removal efficiency lower than $87 \%$ would not be considered as selection. Based on Table 2, it can be clearly identified that all technologies 
have COD removal efficiency lesser than $87 \%$ except MBR which make MBR necessary to be selected as biological treatment technology. In biological treatment, the main factor for technology selection is technology contaminants removal performance instead of operating cost.

In tertiary treatment, since final treated water is just to discharge into water bodies. So multimedia filtration which provide high purity on treated water is not necessary to be selected. Moreover, operating cost of multimedia filtration is the highest among tertiary treatment technologies. By comparing among chlorination and carbon filter, since chlorination operating cost is higher than carbon filter meanwhile chlorination treatment is specific on disinfection which is not necessary for sago wastewater treatment. Thus, carbon filter is selected as tertiary treatment technology.

\section{Conclusion}

A novel MFCA-based approach is developed in this work for optimum pathway selection of wastewater treatment plant. Hidden cost associated to treatment waste stream is considered using this approach for WWTP pathway selection. Case study of sago wastewater is solved to illustrate the proposed approach. Trends of wastewater treatment pathway selection also analysed. In case study, there are several factors such as discharged wastewater quality, technology operating cost and sludge yield that will affect selection of wastewater treatment pathway. To determine minimum THC of WWTP, these factors are traded off by using MFCA based-approach. Thus, this approach can be used as selection tools for decision maker in selection of wastewater treatment pathway so that both economic and environmental aspect can be monitored and improved. This approach could be further extended for systhesis and optimisation of wastewater treatment plant by considering sludge handling technologies and cost.

\section{References}

1. N. K. S. Lawrence K. Wang, Yung-Tse Hung, Handbook of Advanced Industrial and Hazardous Wastes Treatment - Google Books. Taylor \& Francis Group (2010).

2. D. Hoornweg, P. Bhada-Tata, and C. Kennedy, "Environment: Waste production must peak this century," Nature, 502, no. 7473, pp. 615-617 (Oct. 2013).

3. A. Göbel, C. S. McArdell, A. Joss, H. Siegrist, and W. Giger, "Fate of sulfonamides, macrolides, and trimethoprim in different wastewater treatment technologies," Sci. Total Environ., 372, no. 2-3, pp. 361-371 (2007).

4. N. T. Manjunath, I. Mehrotra, and R. P. Mathur, "Treatment of wastewater from slaughterhouse by DAF-UASB system," Water Res., 34, no. 6, pp. 1930-1936 (2000).

5. D. Mamais, D. Jenkins, and P. Prrr, "A rapid physical-chemical method for the determination of readily biodegradable soluble COD in municipal wastewater," Water Res., 27, no. 1, pp. 195-197 (1993).

6. Ekama GA; Marais GvR, "Theory, design and operation of nutrient removal activated sludge processes," (1984).

7. G. Chen, "Electrochemical technologies in wastewater treatment," Sep. Purif. Technol, 38, no. 1, pp. 11-41 (2004).

8. J. K. Edzwald, "Principles and applications of dissolved air flotation," Water Sci. Technol., 31, no. 3-4, pp. 1-23 (1995). 
9. O. Lefebvre and R. Moletta, "Treatment of organic pollution in industrial saline wastewater: A literature review," Water Res., 40, no. 20, pp. 3671-3682 (2006).

10. H. E. Muga and J. R. Mihelcic, "Sustainability of wastewater treatment technologies," J. Environ. Manage., 88, no. 3, pp. 437-447 (2008).

11. W.-W. Li, H.-Q. Yu, and Z. He, "Towards sustainable wastewater treatment by using microbial fuel cells-centered technologies," Energy Environ. Sci., 7, no. 3, pp. 911-924 (2013).

12. R. E. Finger, J. Parrick, and R. E. Finger, "Optimization removal grit a wastewater of at treatment of," 52, no. 8, pp. 2106-2116 (2015).

13. N. Z. Al-Mutairi, M. F. Hamoda, and I. Al-Ghusain, "Coagulant selection and sludge conditioning in a slaughterhouse wastewater treatment plant," Bioresour. Technol., 95, no. 2, pp. 115-119 (2004).

14. P. R. Gogate and A. B. Pandit, "A review of imperative technologies for wastewater treatment I: Oxidation technologies at ambient conditions," Adv. Environ. Res., 8, no. 3-4, pp. 501-551 (2004).

15. P. P. Kalbar, S. Karmakar, and S. R. Asolekar, "Assessment of wastewater treatment technologies: Life cycle approach,” Water Environ. J., 27, no. 2, pp. 261-268 (2013).

16. B. M. Practices, B. Treatment, S. Treatment, and Z. D. Options, "Wastewater treatment technologies," Facilities, 4, pp. 33-43 (1996).

17. N. C. Woods, S. M. Sock, and G. T. Daigger, "Phosphorus recovery technology modeling and feasibility evaluation for municipal wastewater treatment plants," Environ. Technol., 20, no. March 2015, pp. 663-679 (1999).

18. K. V. Gernaey, M. C. M. Van Loosdrecht, M. Henze, M. Lind, and S. B. Jørgensen, "Activated sludge wastewater treatment plant modelling and simulation: State of the art," Environ. Model. Softw., 19, no. 9, pp. 763-783 (2004).

19. V. Albino, E. Dietzenbacher, and S. Kühtz, "Analysing materials and energy flows in an industrial district using an enterprise input-output model," Econ. Syst. Res., 15, no. 4, pp. 457-480 (2003).

20. K. P. Singh, N. Basant, A. Malik, and G. Jain, "Modeling the performance of 'up-flow anaerobic sludge blanket' reactor based wastewater treatment plant using linear and nonlinear approaches-A case study," Anal. Chim. Acta, 658, no. 1, pp. 1-11 (2010).

21. F. Hernandez-Sancho, M. Molinos-Senante, and R. Sala-Garrido, "Cost modelling for wastewater treatment processes," Desalination, 268, no. 1-3, pp. 1-5 (2011).

22. D. J. Dürrenmatt and W. Gujer, "Data-driven modeling approaches to support wastewater treatment plant operation," Environ. Model. Softw., 30, pp. 47-56 (2012).

23. L. Corominas, X. Flores-Alsina, L. Snip, and P. A. Vanrolleghem, "Comparison of different modeling approaches to better evaluate greenhouse gas emissions from whole wastewater treatment plants," Biotechnol. Bioeng., 109, no. 11, pp. 2854-2863 (2012).

24. M. NAKAJIMA, "APO e-Learning Course on Green Productivity and Material Flow Cost Accounting (MFCA) Module," (2012).

25. A. W. Hiroshi Tachikawa, “(NPO)Module1_Day1_Overview_MFCA Mr.Tachikawa_ForDistribution (1).pdf," Propharm Japan Co., Ltd. [Önline]. Available: - https://www.dropbox.com/home/FYP/Concept of MFCA?preview=(NPO)Module1_Day1_Overview_MFCA_Mr.Tachikawa_ForDistrib ution+(1).pdf. (Accessed: 04-May-2017).

26. Y. Furukawa, "APO e-Learning Course on Green Productivity and Material Flow Cost Accounting," no. C (2012). 
27. Y. K. Wan, R. T. L. Ng, D. K. S. Ng, and R. R. Tan, "Material flow cost accounting (MFCA)-based approach for prioritisation of waste recovery," J. Clean. Prod., 107, pp. 602-614 (2015).

28. Yoke Kin Wan, "Syhthesise A Sustainable Sago Industry," (2008).

29. E. Q. A. EQA, "Sewage Characteristics and Effluent Discharge Requirements, Volume4, Section 3.," Malaysian Sewerage Ind. Guidel., 4 (1974).

30. US EPA, “Combined Sewer Overflow Technology Fact Sheet," Environ. Prot. (1999).

31. United States, Environmental Protection, and Agency, "Wastewater Technology Fact Sheet," (1999).

32. P. Molahalli, "Chemical Pre-Precipitation of Municipal Wastewater Treatment," pp. 52, (2011).

33. A. O. Tanyi, "Comparison of Chemical and Biological Phosphorus Removal in Wastewater - a Modelling Approach," pp. 72-78 (2013).

34. I. Hamawand and N. Centre, "Review of wastewater treatment chemicals and organic chemistry alternatives for abattoir effluent," pp. 1-67 (2015).

35. F. A. Brinson et al., "Evaluating Nanofiltration, Reverse Osmosis, And Ion Exchange To Meet Consumptive Use Constraints And Finished Water Quality Goals For Broward County Scope of Analysis," (2002).

36. M. M. Socías-viciana, "Coagulation-flocculation of domestic wastewater by moroccan clays : Removal of organic matter and suspended solids Moroccan Clays : Removal Of Organic Matter," (April 2016, 2014).

37. A. G. Kapagiannidis, I. Zafiriadis, and A. Aivasidis, "Upgrading the efficiency of an external nitrification BNR system - The modified Dephanox process," Chem. Eng. J., 175, pp. 124-135 (2011).

38. K. Kim, "The characteristic of the sequencing batch reactor (SBR), anaerobic sequencing batch reactor (ASBR) and sequencing batch biofilm reactor (SBBR) Koobum Kim," Most (2011).

39. A. Aygun, B. Nas, and A. Berktay, "Influence of High Organic Loading Rates on COD Removal and Sludge Production in Moving Bed Biofilm Reactor," Environ. Eng. Sci., 25, no. 9, pp. 1311-1316 (2008).

40. T. M. Huggins, A. Haeger, J. C. Biffinger, and Z. J. Ren, "Granular biochar compared with activated carbon for wastewater treatment and resource recovery," Water Res., 94, pp. 225-232 (2016).

41. M. L. Gulhane and A. U. Charpe, "Domestic Wastewater Treatment using Multimedia Filter Technology," 3, no. 1, pp. 1119-1121 (2015).

42. F. Jiang, M. Beck, R. Cummings, and K. Rowles, "Estimation of costs of phosphorus removal in wastewater treatment facilities: construction de novo," Water Policy Work., no. June, pp. 1-28 (2004).

43. A. Wendland and Y. Ozoguz, "Operation Costs of Wastewater Treatment Plants," (2013). 